\title{
n lenguaje compartido: La Antropología en el TPHA
}

\section{Juan Agudo Torrico Antropólogo. Universidad de Sevilla}

\section{Elodia Hernández León Antropóloga. \\ Centro de Documentación} del IAPH

\section{Resumen}

En estás páginas analizamos cómo la construcción de un lenguaje documental sobre nuestro patrimonio ha parte de su definición. Los términos que se incluyen responden a un concepto amplio en el que tiene cabida el patrimonio etnológico y por tanto no sólo refiere a los artefactos materiales sino también a los acontecimientos inmateriales y en definitiva a la significaciones y valores culturales de nuestro patrimonio.

\section{Palabras claves:}

Tesauros / Patrimonio Histórico / Andalucía / Cultura / Patrimonio Etnológico / Antropología

\section{Las palabras no inocentes}

Todo Tesauro tiene por finalidad la doble pretensión de una homogeneización y normalización terminológica en razón de la temática o disciplina que aborde, y en segundo lugar de favorecer la sistematización del proceso de documentación con la finalidad de una fácil recuperación de la información acumulada. Cuando se aplica al Patrimonio Histórico, no debemos olvidar que la propia consideración de que es lo que forma parte de este patrimonio no sólo ha sido y es cambiante en cuanto a sus contenidos materializables (qué edificios se seleccionan, objetos que pasan a formar las colecciones de un museo, etc.) sino en los valores sociales a partir de los cuales se define este patrimonio; $y$ en este sentido, un buen ejemplo lo constituye la propia modificación de la terminología con la que se ha ido definiendo a lo largo de este siglo, desde aquellos tesoros nacionales en sus comienzos, al patrimonio histórico-artístico de los años treinta, al histórico según la legislación vigente, y al uso más común de patrimonio cultural como globalidad al que nos solemos referir habitualmente en textos y comentarios.
En una palabra, al hablar de patrimonio, aunque todos tengamos en mente algún monumento más o menos emblemático, en la realidad lo hacemos de valores y conceptos a partir de los cuales dotamos de significado a los testimonios elegidos. Sin embargo, variables tales como tiempo pasado, singularidades estéticas, escasez, etc. han sido y siguen determinando la imagen más tradicional de lo que se ha dado en llamar patrimonio hegemónico. Factores que pueden combinarse con otra serie de clasificaciones formales que permiten agrupar a estos elementos en una lógica definida por los periodos históricos, estilos artísticos, y funciones y utilidades que desempeñaron.

Este tipo de patrimonio histórico, ya consolidado en la imagen colectiva, estará representado por una considerable variedad de objetos muebles e inmuebles que es preciso clasificar y definir con precisión. Pero ¿Qué ocurre con el patrimonio etnográfico?

Se trata de un patrimonio que es recogido por primera vez en la Ley del Patrimonio Histórico Español de 1985, y después en la Ley del Patrimonio Histórico de Andalucía de 1991, y por lo tanto sus contenidos potenciales deben formar parte de este Tesauro en igualdad de condiciones que cualquier posible referencia a las demás subdivisiones teórico-metodológicas en las que fragmentemos el contenido del patrimonio histórico andaluz. Pero si leemos las definiciones que se hace de este patrimonio etnográfico en ambos textos, nos aparece más que cualquier precisión en sus contenidos, los valores desde los que han de ser definidos y seleccionados los testimonios que elijamos por formar parte de una cultura tradicional que nos habla de la diversidad de modos como se expresa la identidad de un pueblo.

El patrimonio etnográfico abarca tanto a los bienes muebles e inmuebles, que pueden seguir en uso o formar parte de un pasado reciente, no sentido aún como historia, formados fundamentalmente por referentes que en gran medida quedan fuera de las imágenes más consolidadas de monumentalidad, ri- 
Definimos una organización de los descriptores (...) que no sólo está referida a la materialidad concreta del bien cultural sino también a sus simplificaciones socioculturales.

queza material, particularismos estéticos, etc. que caracterizan a los bienes integrados en el que hemos denominado patrimonio hegemónico. Constituyen, en definitiva, los testimonios de un mundo cotidiano hasta ahora sólo valorados si dichos objetos tienen ya la condición de arqueológicos.

Pero la cuestión se hace más compleja si tenemos en cuenta que forman parte de este patrimonio etnográfico bienes circunscritos no sólo al ámbito de lo material en el sentido estricto de la palabra (bienes muebles e inmuebles), sino también al de lo inmaterial (cultura inmaterial o intangible) formado por saberes, prácticas, conocimientos, actividades, que son o han sido relevantes en la cultura tradicional del pueblo andaluz.

La filosofía de la Ley no es otra que la pretensión de amparar todo referente cultural significativo que testimonie la evolución y conformación de la cultura andaluza, insertando dichos testimonios en contextos históricos concretos, y en el caso del patrimonio etnográfico en relación con los modos de vida más recientes manifiestos a través de los sistemas productivos, organización social, y los muy diversos y complejos modos de expresión (rituales, fiestas, música, etc.) de las creencias religiosas, valores sociales, expresiones estéticas, etc. Todo ello justificados en su elección y tamizados a partir del criterio determinante de formar parte relevante de nuestra historia y cultura y contribuir a perfilar los rasgos que hoy conforman la identidad andaluza.

Ello hizo, como quedó bien de manifiesto en las discusiones teóricas sobre determinados vocablos, que se planteara la necesidad de que aparecieran términos asociados a valores, formas de organización, creencias, etc. sin los cuales no se podrían ni valorar ni justificar una parte considerable de nuestro patrimonio cultural andaluz. Con la circunstancia de que esta demanda no solo afectaba a los términos usados habitualmente en la disciplina antropológica y más directamente relacionados con sus objetos de trabajo, (en el caso de la ley del Patrimonio Histórico, en re- lación con el patrimonio etnográfico o a la hora de definir los lugares de interés etnográfico) sino que los mismos vocablos y los conceptos que irían detrás eran reclamados también por la arqueología a la hora de dotar de significados a los propios objetos, artefactos, con los que trabajaban y su articulación con los modos de vida y características de las sociedades extintas que pretenden reconstruir.

De esta forma, reconocida la dificultad a la hora de plasmar estos valores, sistemas organizativos, etc. es como adquiere su pleno valor la importancia dedicada al macro de Estructuras, o, sin que nos podamos detener ahora en otras muchas cuestiones sumamente interesantes acerca de las discusiones dentro del equipo de trabajo sobre la inclusión o no y su representatividad, la aparición y diferencias entre género y sexo que nos llevó a diferenciar además de hombres y mujeres, homosexuales, ... ; la importancia dada a los acontecimientos sobrenaturales y actividades mágico religiosas; sistemas de organización social y política, etc. Los descriptores que aparecen dentro de estas clasificaciones no sólo se materializarán en determinados artefactos materiales (imágenes y objetos religiosos, vestimentas, edificios) sino también en otros acontecimientos culturales inmateriales que pueden ser igualmente patrimonializables de acuerdo con la Ley de 1991, tal y como esta ocurriendo con las propuestas ya hechas para incluir en el Catálogo General de determinados rituales y fiestas tradicionales.

En definitiva, en muchos casos son descriptores que están referidos a unos valores. No podemos olvidar que las palabras no siempre tienen un mero sentido descriptivo, ideográfico, sino que en muchos casos se revisten de un valor connotativo, con lo que la combinación de los diferentes descriptores pueden acercarnos a los significados más precisos de aquellos referentes elegidos entre nuestro patrimonio etnográfico. Esa ha sido la intencionalidad en la aportación que se ha pretendido desde la antropología, definiendo una organización de los descriptores que posiblemente haya que revisar en cuanto a las exclusiones y las carencias concretas pero que nos han permitido introducir las 

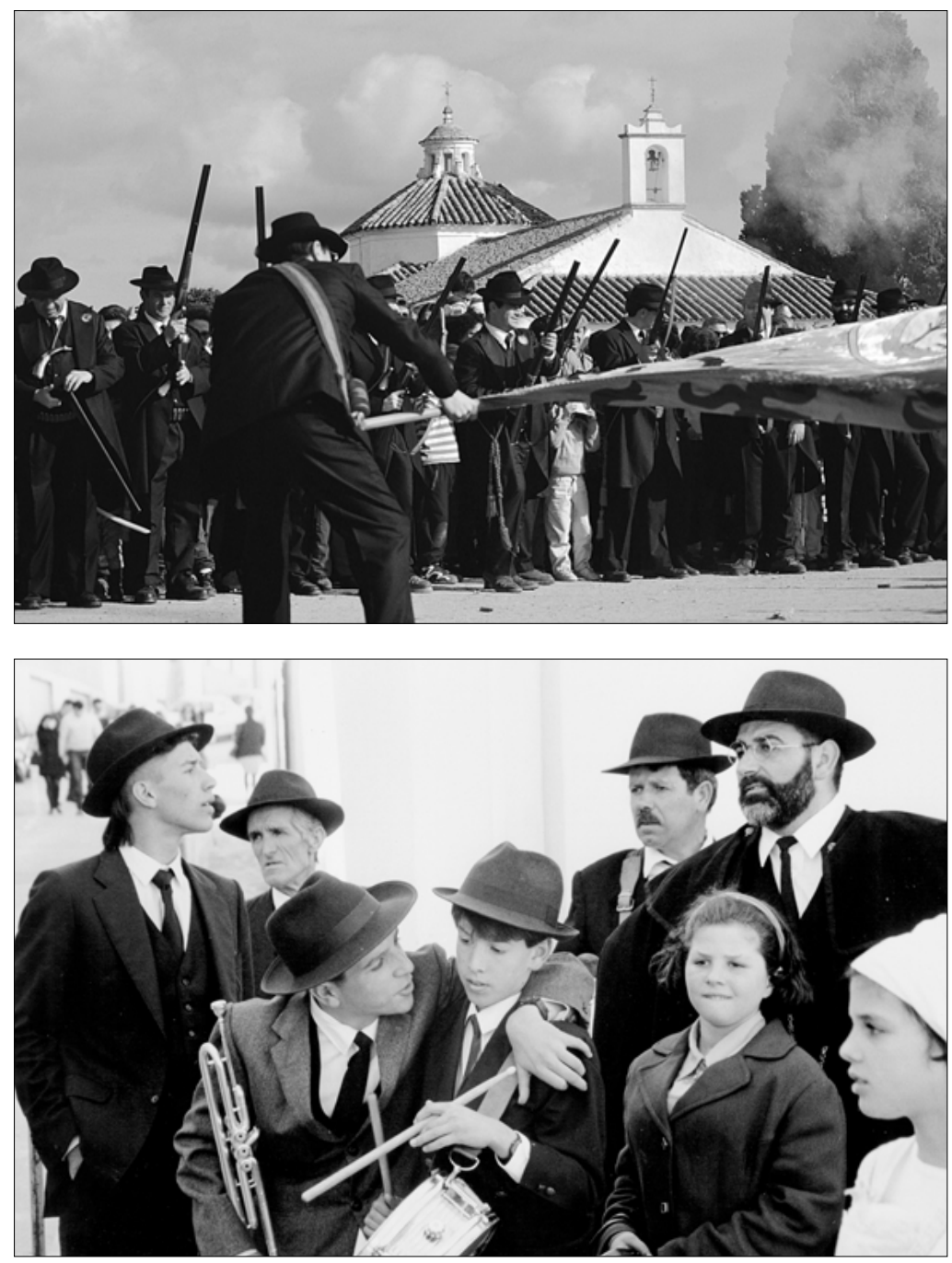

Foto autor:

José Carlos Roldán

José Antonio Flores (Fototres) variables de clasificación y recuperación de una información que no sólo está referida a la materialidad concreta del bien cultural de turno, sino también a sus significaciones socioculturales.

\section{La construcción del lenguaje y la mirada antropológica}

La elaboración del Tesauro de Patrimonio Histórico Andaluz fue un reto para nosotros. Un reto y una apuesta. Apostamos por formar parte activa en un equipo multidisciplinar que trabajara en un proyecto común y único, con una metodología superadora de la tendencia a seguir trabajando "cada uno su parcela" que continua vigente en muchos de los equipos formalmente constituidos como multidisciplinares.

Era un reto porque la antropología, más en concreto, la información sobre el patrimonio de interés etnológico, no contaba con una tradición en la catalogación tan amplia como otras disciplinas I. Sin embargo el creciente desarrollo de la información sobre éste requería un adecuado tratamiento para su transferencia a la sociedad.
En nuestro caso por tanto el reto era doble: avanzabamos al mismo tiempo en el lenguaje documental y en los criterios metodológicos de inclusión y análisis de la información en las bases de datos sobre le Patrimonio Histórico, apoyándonos en la experiencia que con respecto a estas herramientas tenían otras disciplinas.

Si en el caso de otras disciplinas el TPHA, tal como se decidió abordar por el grupo de trabajo como un lenguaje de integración de las distintas áreas de conocimiento, se presenta como una novedad sobre los antecedentes ${ }^{2}$, también para nosotros. Aunque contábamos con algunas experiencias que nos sirvieron como punto de partida. Nos referimos al Sistema de Clasificación de Documentación Etnográfica Española elaborado en 1993 para su aplicación a los fondos de documentales y museográficos del Museo del Pueblo Español, que si bien no contempla un desarrollo terminológico concreto, si es cierto que sus grandes perchas nos dieron algunas pistas en la organización jerárquica de los listados.

La primera preocupación del grupo de trabajo fue el establecimiento de una macroestructura a modo de armazón que fuera sometiéndose a distintas pruebas de resistencia según avanzábamos en el desarrollo de la terminología. La discusión y definición de esta no hizo sino reafirmarnos en aquella postura adaptada por el grupo de trabajo y con anterioridad por los promotores del TPHA (El Centro de Documentación del IAPH): podíamos desarrollar un lenguaje integrado puesto que el "alma" de éste era aceptable para todos.

Aunque la macroestructura que abre el abanico a las relaciones y listados jerárquicos no es la única forma para acceder a los términos del TPHA, constituyó la base a partir de la que ir interrogando la realidad patrimonial andaluza, es decir a la inclusión de los términos.

Por ello la aceptación de las grandes macrocategorías, que organizadas alfabéticamente daban luz a la macrotestructura, fue un importante paso que resistiría muchos de los momentos críticos derivados de las distintas valoraciones sobre la prioridad de un término sobre otro, ya que el orden jerárquico resulta conflictivo. La ubicación concreta de cada descriptor en la estructura jerárquica es difícilmente aceptable por quienes hacen análogo el orden de colocación con el de privilegio de unas disciplinas respecto a otras.

Sin embargo aprehendimos, y asumimos en común, esta primera estructura a partir de la que desarrollar un trabajo en el adoptamos muchos otros consensos y convenciones en el marco de esa negociación que se establece en el momento en que se sientan en una mesa muy diferentes miradas sobre nuestro patrimonio.

Una vez aceptada la macroestructura descendimos al micronivel, a la búsqueda y aceptación de los térmi- 
nos que engrosan el TPHA. A pesar de que en principio las grandes categorías no respondían cada una a una disciplina concreta, el trabajo se organizó por afinidades o empatía de las disciplinas con respecto a determinadas secciones. De esta forma participamos especialmente en la organización de las macrocategorías funcionales, relacionadas con las acciones y agentes humanos. Es el caso de los grandes macrodescriptores 100000 Acontecimientos, Actividades. Procesos. Técnicas y 20000 Agentes. Y también nos implicamos de lleno en el caso de la sección de objetos relacionados con las acciones y procedimientos (7210000 Utensilios en la macro de Objetos) y aquellas como 5000000 Estructuras en la que se recogen los conceptos teóricos y abstracciones que describen o analizan los sistemas socioculturales. Del mismo modo que por poner un ejemplo, básicamente al arquitecto correspondería la sección de 7100000 Objetos Inmuebles.

No se entienda con ello, que hubo una aportación exclusivista sobre estas secciones puesto que las propuesta de inclusión/exclusión de términos se hizo en todos los "frentes", además podemos decir que cada uno de los descriptores que componen el corpus del Tesauro han sido revisados y aprobados por el grupo en sesión de trabajo. Si es cierto que por la mayor preocupación de nuestra mirada sobre aquellos términos que pueden ser necesarios para la normalización de las actividades socioeconómicas y culturales así como de las personas, grupos e instituciones, nos ocupamos especialmente de las mencionadas macrocategorías.

Para su organización establecimos amplios campos, términos o niveladores genéricos en los que incluir en distintos niveles, encadenados, los descriptores necesarios. Nuestra estrategia fue el mantenimiento de una misma estructura de organización de los campos, siempre que fuera factible, una vez estuvieran completos los términos que iban a formar parte del TPHA. Nos referimos por ejemplo a cómo el nivelador Actividades de transformación* ${ }^{3}$, referido a todas aquellas actividades en las que se emplean acciones sobre materiales para la obtención de productos, se encuentra también en el caso de la macrocategoría agentes (Agentes de transformación*) o en el caso de las técnicas (Técnicas en Actividades de transformación*). O en un nivel más de profundidad por ejemplo encontramos Transformación de materia animal, Agentes en transformación de materia animal, o Técnica de transformación de materia animal.

Por tanto trabajamos arrastrando una organización de los niveles en paralelo, aunque esta no se mantuvo invariable siempre, se repite con asiduidad, de forma que el catalogador y el usuario en general pueda hacerse más fácilmente con el corpus del TPHA y la filosofía de aproximación a la realidad patrimonial que encierra.

Sin embargo esta estructura no está "calcada" en todas las macrocategorías sino que presenta cambios en función de la importancia y características de los descriptores a los que nos refiramos. Este es el caso de las técnicas, sección especialmente compleja. En ella se recogen el amplio abanico de procedimientos y fases técnicas derivados de las distintas actividades, supone en este sentido, un desarrollo en un nivel micro de éstas.

La compilación de términos en esta sección tenía para nosotros al menos dos problemáticas dignas de mencionarse: la limitación que suponía la inclusión de los procedimientos mediante un descriptor en lo posible compuesto por un sólo término y por otro lado la existencia de descriptores semejantes para los procedimientos técnicos relacionados con unas actividades y otras. Con respecto a la complejidad de las denominaciones de algunas técnicas, que no cuentan con vocablos tan concretos y específicos como otras (por ejemplo las relacionadas con actividades artísticas), la resolvimos recurriendo a algunos descriptores que pueden considerarse un tanto "forzados" si tenemos en cuenta que generalmente se denominan con amplias oraciones.

Por otro lado la gran coincidencia de procedimientos técnicos en muy diferentes actividades y desde la implicación de las distintas disciplinas nos llevó al grupo de trabajo a optar por otra estrategia a la seguida en la macrocategoria de Actividades, aunque acudiendo a un criterio que no era nuevo y se había seguido en otros casos. Nos referimos a la localización en los distintos listados que habíamos elaborado, de procedimientos comunes diferenciándolos de aquellos específicos y de gran importancia en la documentación de nuestro Patrimonio Histórico.

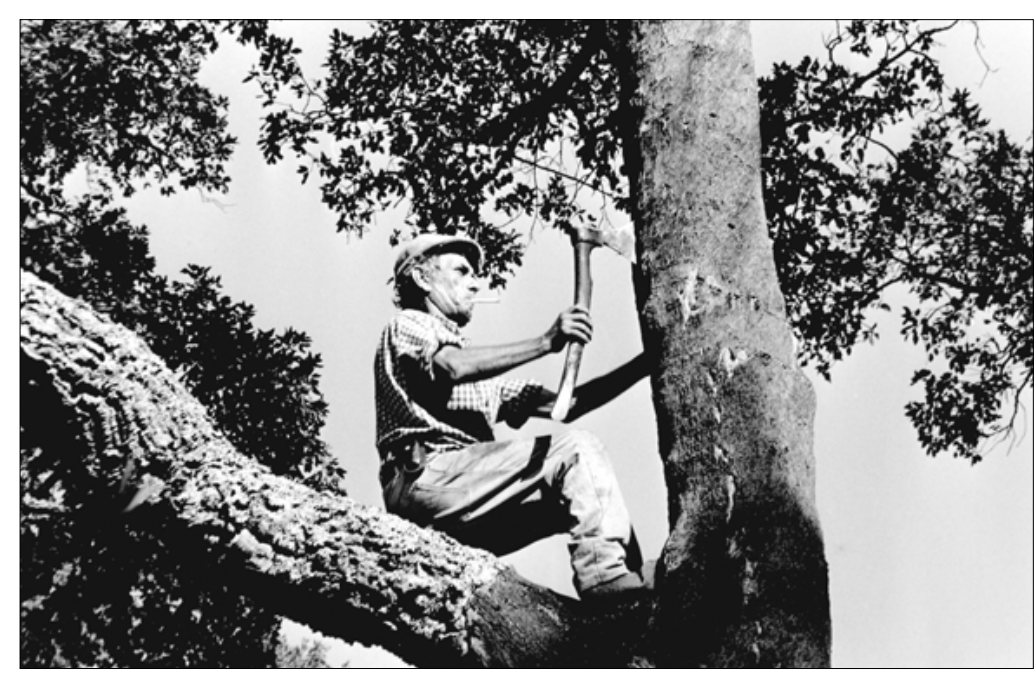

Foto autor:

Finalmente la sección quedó organizada de forma mixta. Siguiendo un criterio descriptivo para las técnica comunes (Técnica de corte*...) y manteniendo la clasificación que habíamos seguido en la macro de actividades (Técnica en actividades primarias*...) .

Es lógico pensar que en el caso de los Utensilios que intervienen en las distintas acciones y procedimientos 
Fig. 1

\begin{tabular}{|c|c|}
\hline - Cuchillas & $\begin{array}{l}\text { - Utensilios de apicultura } \\
\text { - Utensilios de guarnicionería } \\
\text { - Utensilios de curtiduría } \\
\text { - Utensilios de cestería } \\
\text { - Utensilios de zapatería } \\
\text { - Utensilios de tonelería } \\
\text { - Utensilios de ... }\end{array}$ \\
\hline - Cuchillas & - Utensilios de corte \\
\hline
\end{tabular}

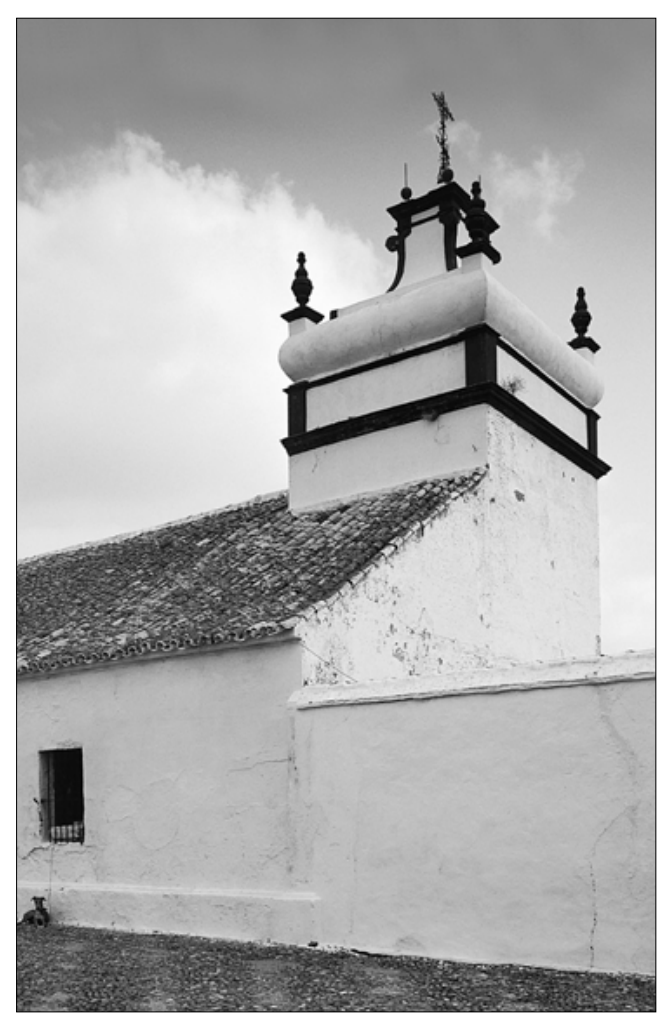

la problemática que surgió fue semejante. No se podía mantener una estructura niveladora "calcada" de la de actividades, no sólo porque "nuestros utensilios" eran utilizados en muchas y diversas actividades sino porque dentro de aquellas que desarrollamos basándonos en la documentación antropológica disponible, la coincidencia era muy alta (figura I). El grupo de trabajo optó por la búsqueda de unas etiquetas descriptivas que dan entrada a los campos donde se alojan los distintos utensilios, basándonos en lo que denominábamos "funciones primarias" frente a los niveladores temáticos de las actividades.

Podríamos seguir exponiendo muchos otros aspectos del proceso de construcción del TPHA, pero no queremos hacer de estas páginas una memoria comprimida de tres largos años. Por ello hemos optado por hablar de algunas de las estrategias que a nuestro juicio son más trascendentes para entender la participación de los antropólogos en este proyecto.

Sin embargo merece la pena detenerse en un recurso que aceptamos para evitar la inflación de términos. La lucha contra los números exorbitados derivados de la acumulación de términos a medida que avanzábamos en el desarrollo de los campos, nos hizo aceptar plenamente este recurso que además expresaba una concepción del lenguaje más flexible. De la misma forma que acordamos, no sin arduos debates, la construcción de un lenguaje integrado y único para todas las disciplinas, entendimos el recurso a la poscoordinación y a la elimimación, salvo casos excepcionales, de las precoordinaciones una vez fuimos conscientes de que nos llevaban a la multiplicación de descriptores, sino al infinito.

Y ello está relacionado con esa mayor empatía que fue adoptando el grupo de trabajo hacia las relaciones asociativas frente a las jerárquicas, hacia esa posibilidad horizontal de encadenamiento de los térmi-

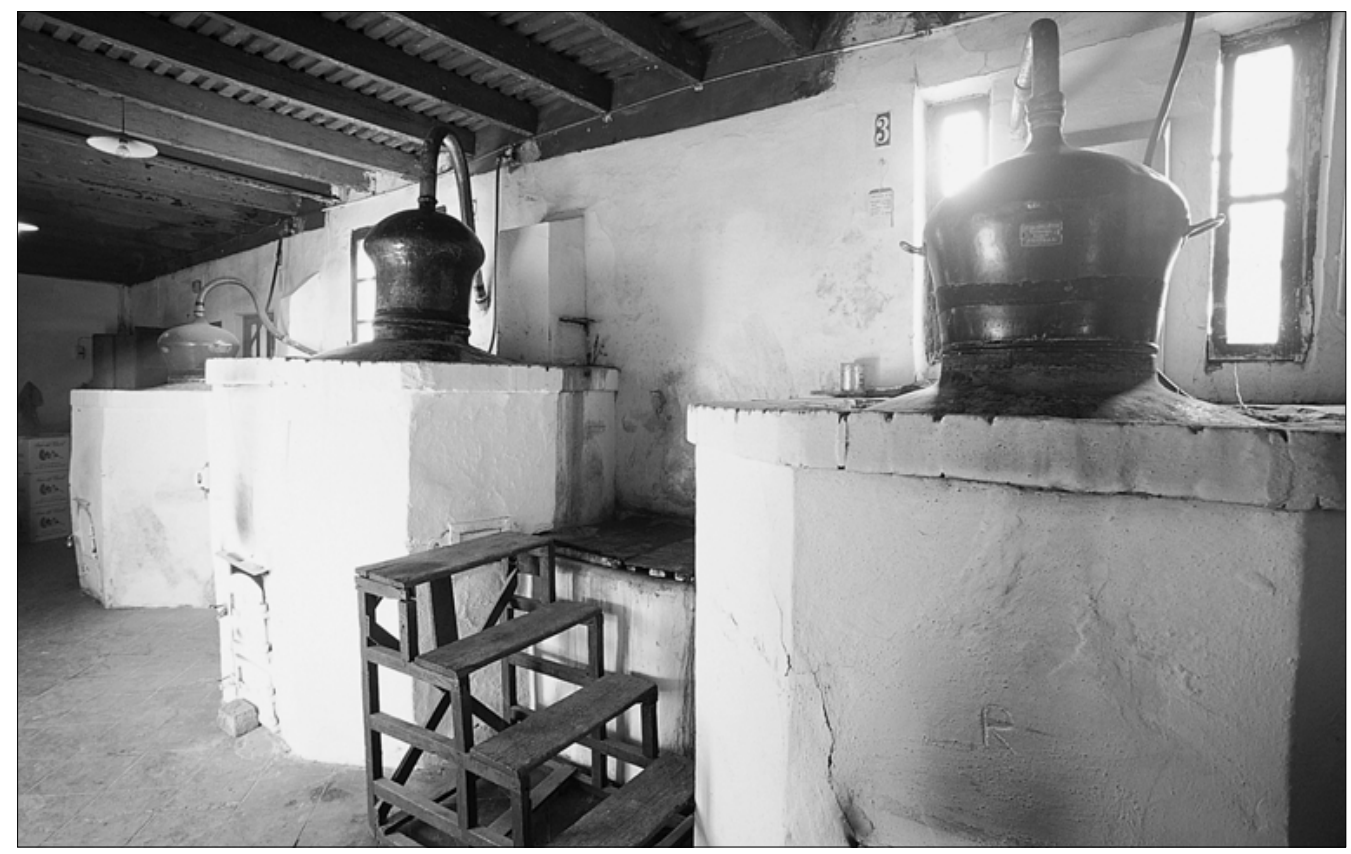


nos que chocaba con la generalizada identificación entre normalización terminológica y listados cerrados. Existe un operador de asociaciones (TR) que, entre otras sugerencias, nos ofrece la posibilidad de indicar al usuario, que viaja recorriendo el tesauro, poscoordinaciones.

Elaboramos un tesauro que sobrepasaba con mucho los términos previstos en un principio. Una primera versión que toma el carácter de propuesta y debe ser analizada, revisada y completada. El especialista en algún tema en concreto podrá echar de menos algunos términos, otros encontrarán excesivo, el nivel de profundización en algunos campos, sin embargo la cuestión no es la falta de algunos términos que se podrán añadir en futuras versiones, sino si la estructura del tesauro resulta valida globalmente para responder a muy diversas necesidades.

Con la presentación del TPHA finaliza una primera etapa, pero comienza otra de utilización y adecuación de este lenguaje a las herramientas de documentación. Hemos construido un lenguaje integrado a la vez que entendible desde una mirada antropológica. Hay que aproximarse a él partiendo de sus normas básicas para que se nos abra como un lenguaje de fácil manejo 4 .

El TPHA no ha dejado de ser un reto, continúa siéndolo para aquellos que apostamos por una documentación del patrimonio coherente con una visión integrada e integradora.

\section{Notas}

I. Una revisión de los inventarios realizados hasta los años noventa manifiesta este vacío. Pero la falta de presencia en los distintos inventarios y catalogaciones en absoluto significa una carencia de avances en la investigación sobre el patrimonio andaluz, antes al contrario, la investigación de nuestra cultura es un pilar básico de la antropología andaluza desde sus inicios en los años setenta. Es en los años noventa cuando comienzan toda una serie de iniciativas para suplir la carencia de instrumentos de conocimiento del patrimonio etnológico. Inventarios de Arquitectura Popular como el iniciado por la Dirección General de Bienes Culturales de la Consejería de Cultura y otros más localizados por áreas o tipologías concretas.

2. Nos referimos a los antecedentes más concretos y parciales con los que contamos. Por ejemplo el Chenhall 1978, Tesauro de Iconografía Garnier 1981, y el más amplio Tesauro de Arte y Arquitectura ATT de la Paul Getty (MARTÍN PRADAS, Antonio: "Los tesauros en el mundo de los museos". Sevilla 2000 s.p.
3. Reproducimos estas etiquetas como se encuentran en el TP$\mathrm{HA}$. El asterisco indica que son niveladores, no son términos de indización.

4. En distintas experiencias con grupos tras unas sesiones de introducción, la navegación por el TPHA se torna fácil. Es el caso por ejemplo de la sesión teórico-práctica realizada en Marzo dentro del curso "Antropología y Patrimonio: métodos de normalización documental e intervención" Universidad de Sevilla-IAPH. 